\title{
Surgical Management of Orbital Fractures Using X-ray Film Plate: a Retrospective Case Series
}

\author{
Zahid Kamal Siddique1, Qudsia Anwar Dar ${ }^{2}$, Amna Farooq ${ }^{3}$, Muhammad ljaz Anjum ${ }^{4}$ \\ Muhammad Mohsin $\mathrm{Ali}^{5}$ \\ 1,2,3,5 Department of Ophthalmology, King Edward Medical University/Mayo Hospital \\ ${ }^{4}$ Lahore General Hospital, Lahore
}

\begin{abstract}
Purpose: Orbital trauma is associated with orbital blowout fractures, with associated globe injuries and loss of vision. Orbital reconstruction can be done with various implant materials. The aim of this study is to identify the safety and postoperative outcomes of using X-ray films as orbital implants during orbital reconstruction surgery.

Study Design: An interventional case series.

Place and Duration of Study: Ophthalmology departments of Lahore General Hospital and Mayo Hospital, Lahore from June 2001 to May 2017.

Methods: Retrospective data of all the patients who came for orbital reconstruction surgeries from June 2001 to May 2017 was retrieved. All patients had undergone CT scan prior to surgery. Orbital reconstruction was done by a single surgeon, by bridging bony defect with sterilized X-ray film. All patients received post-operative antibiotics for 1 week.

Results: Twenty three male patients were included in the series, with a mean age of $28 \pm 2.47$ years. Assault and sports injuries with a ball were the commonest form of trauma. Diplopia was the major presenting complaint in $91 \%$ of the patients. All patients underwent surgical reconstruction of the orbital floor of orbit with sterilized X-ray film using a lateral canthotomy approach. Only mild postoperative diplopia was recorded in 7 of the cases, with uneventful recovery in the majority.
\end{abstract}

Conclusion: Sterilized X-ray film is a safe, cost effective, and durable material for reconstruction after orbital blowout fracture, especially in developing countries.

Key Words: Orbital fracture, X-ray film, Diplopia.

How to Cite this Article: Siddique ZK, Dar QA, Farooq A, Anjum MI, Ali MM. Surgical Management of Orbital Fractures Using X-ray Film Plate: a Retrospective Case Series. Pak J Ophthalmol. 2021, 37 (2): 156-160.

Doi: http://doi.org/10.36351/pjo.v37i2.1111

\section{INTRODUCTION}

Orbital trauma is a common presentation for patients presenting to oculoplastic surgical units. When a blunt

Correspondence: Qudsia Anwar Dar

Department of Ophthalmology, King Edward Medical University, Mayo Hospital, Lahore

Email: qudsiaabbas@gmail.com

Received: July 27, 2020

Accepted: January 16, 2021 rounded object of diameter more than $5 \mathrm{~cm}$ hits the orbit, there is a sudden rise in orbital hydraulic pressure, which can result in fracture of the orbital wall with bony fragment moving out of orbit along with the soft tissue; thisis labelled as orbital blow out fracture $(\mathrm{OBF})$. If there is no involvement of the orbital rim or facial bones it is called pure OBF. ${ }^{1,2}$ Fractures of the orbital wall are classified as either isolated fractures, where a single orbital wall is involved; or as combined fractures, when more than one orbital wallsare involved. Out of all the four orbital walls, the floor of orbit is the most frequently 
injured. It contains the largest open space and it lacks structural support, henceit is often fractured following blunt traumas of the face and orbits. The frequency of orbital floor fractures is becoming more common due to the increasing number of traffic accidents, sportsrelated injuries and physical aggressions. ${ }^{3}$

Repair of orbital wall and floor fractures can be challenging due to the demanding three-dimensional anatomy and limited intraoperative view. Poorly fitted implants and inaccurate surgical technique may lead to visual disturbance and unaesthetic results. ${ }^{3}$ Moreover, the cost of implants is a barrier towards appropriate management in the developing countries.

The goal of orbital reconstruction is to repair trauma related defects; to correct the anatomical position of the eye; torestore the volume of the orbit; to avoid enophthalmos and diplopia; and to restore ocular function. There is no ideal implant for orbital fracture reconstruction. Recently published studies have highlighted following points for a suitable orbital implant for repair of orbital blow out fractures: (1) stability and fixation; (2) contouring and handling; (3) biological behavior; (4) donor site morbidity; (5) radio-opacity (6) availability (7) cost-effectiveness. ${ }^{4-8}$ A variety of implants have been reported including; bone, cartilage, Titanium mesh, porous polyethelene and Teflon. ${ }^{9,10}$ However, the cost and availability of these implants is often a restricting factor for oculoplastic surgeons in developing countries.

A sterilized X-ray film is advantageous for orbital floor reconstruction as it is easily available with cheap cost. Being a semi-rigid material, inert and a smooth surface it can be easily sterilized using a standard $134^{\circ} \mathrm{C}$ autoclave cycle. It provides adequate support and is well-tolerated by orbital tissue. It can be easily trimmed with a pair of heavy scissors to cover the bony defect. Its smooth surface may also help to reduce the risk of postoperative adhesions and restrictive strabismus. ${ }^{9}$

The purpose of this study was to assess the efficacy and safety of X-ray film plate as an orbital floor implant to repair OBF. Multicenter experience of a single surgical operator is presented with record of postoperative complications to show that X-ray film plates can be an efficient alternative implant in lower middle income countries.

\section{METHODS}

A retrospective analysis of patients with orbital fractures, who presented to the ophthalmology departments of Lahore General Hospital and Mayo Hospital, Lahore, was conducted. Only those cases, which required surgical intervention were included in this study. The study period included all cases from June 2001 to May 2017. Those cases with adjacent facial fractures or associated head injury were excluded from the study.

The globe injuries were identified and treated. Extra ocular movements were recorded as a percentage of the normal movements. All patients underwent computed tomography of the head and orbits with axial and coronal sections of $2-3 \mathrm{~mm}$ and bone windows. The indications for repair of the fracture were persistent diplopia, hypophthalmos or enophthalmos and a large fracture $(>50 \%$ of orbital floor).

All the procedures were performed under general anaesthesia. The surgeon used a head mount light for coaxial illumination. Lateral canthotomy was done and the inferior orbital rim was exposed through a transconjunctival approach. The orbital periosteum was lifted and orbital wall fracture was identified. Free bony fragments were removed and orbital soft tissue contents were retrieved from the adjacent para-nasal sinus. The defect in the bone was bridged with a sterilized X-Ray film cut to appropriate size. The periosteum, conjunctiva and lateral canthotomy were closed by absorbable sutures in separate layers. A light patch was applied at the end of procedure. All the patients were given oral cephalosporins (cefuroxime) for 1 week. They were advised to avoid blowing their nose. Cold compresses were done 8 hourly using ice packs in a sterilized glove. Visual functions (Visual acuity, colour vision and Pupillary light reaction) were recorded 6 hourly in the first 24 hours after the surgery to identify any optic nerve compression secondary to post-operative intra-orbital bleeding. The patients were followed for at least two months. Any complications that occurred in the postoperative periodwere recorded. Postoperative diplopia was recorded as mild, moderate or severe on basis of ocular motility restriction; in mild cases, $75 \%$ movement beyond the midline was possible, while in severe cases, $25 \%$ or no movement was possible beyond the midline.

Permission was taken from the Institutional Review Board of the concerned institutions for the use of patient data. All ethical considerations were followed by the authors in data collection. SPSS 
software version 23 was used for data analysis, with qualitative statistics reported as frequency and percentages, and quantitative statistics as mean \pm SD.

\section{RESULTS}

Twenty-three patients were included in this study. All of the participants were males, ranging from 13 to 49 years of age. The mean age in the study was $28 \pm 2.47$ years. The underlying causes of the fractures are summarised in table 1 .

Table 1: Cause of injury and presenting symptom.

\begin{tabular}{ll}
\hline Cause of Injury & N (\%) \\
\hline Assault & $08(35)$ \\
Sports & $07(30)$ \\
Motor Vehicle Accidents & $08(35)$ \\
Symptoms & $\mathbf{N}(\%)$ \\
Diplopia & $21(91)$ \\
Hypaesthesia & $08(35)$ \\
Lid ecchymosis & $08(35)$ \\
Enophthalmos $>2 \mathrm{~mm}$ or hyophthalmos & $05(22)$ \\
\hline
\end{tabular}

The sources of injury in cases of trauma and assault were punch by a closed fist or a ball. It was difficult to establish the exact source of injury in cases of motor vehicle accidents. The clinical presentation of patients is shown in table 1 .

The ophthalmic examination showed subconjunctival haemorrhage $(\mathrm{n}=5)$, hyphema $(\mathrm{n}=2)$ and globe rupture $(n=1)$. The interval between injury and presentation ranged from 0 to 7 days (mean $4 \pm$ 0.73 days). The interval between injury and surgery ranged from 3 to 16 days (mean $13 \pm 0.85$ days).

In $87 \%$ of the cases, CT scan of the orbit revealed fracture of the orbital floor only, whereas in $13 \%$ of the cases it showed fracture of both the orbital floor and the medial wall of the orbit. No significant intraoperative complications were recorded. Only minor postoperative complications were noted: in one case, lateral canthal pyogenic granuloma developed, for which excision and thermal cauterization was done. In another case, there was anterior migration of the X-ray film plate, which was removed without affecting the ultimate results. The final outcome regarding diplopia is summarised in table 2.

Wilcoxon Signed Rank test showed mean rank of 3.5 and 13.28 for preoperative diplopia and postoperative diplopia respectively with $\mathrm{z}=-3.753$ and $p=0.000$, signifying that $X$-ray film implant corrected diplopia significantly.

Table 2: Postoperative diplopia $(n=23)$.

\begin{tabular}{ll}
\hline Grading of Diplopia & N (\%) \\
\hline None & $13(56.5)$ \\
Mild & $07(30)$ \\
Moderate & $01(4.3)$ \\
Intermittent & $02(8.6)$ \\
\hline
\end{tabular}

\section{Ranks}

\begin{tabular}{llrrr}
\hline Diplopia & & N & $\begin{array}{r}\text { Mean } \\
\text { Rank }\end{array}$ & $\begin{array}{r}\text { Sum of } \\
\text { Ranks }\end{array}$ \\
\hline & Negative Ranks & $4^{\mathrm{a}}$ & 3.50 & 14.00 \\
Pre-operative & Positive Ranks & $18^{\mathrm{b}}$ & 13.28 & 239.00 \\
Post-operative & Ties & $1^{\mathrm{c}}$ & & \\
& Total & 23 & & \\
\hline
\end{tabular}

a. pre-operative diplopia < postoperative diplopia

b. pre-operative diplopia>postoperative diplopia

c. pre-operative diplopia $=$ postoperative diplopia

Test Statistics ${ }^{\mathrm{a}}$

\begin{tabular}{lc}
\hline & $\begin{array}{c}\text { pre-operative Diplopia - } \\
\text { Post-operative Diplopia }\end{array}$ \\
\hline $\mathrm{Z}$ & $-3.753^{\mathrm{b}}$ \\
Asymp. Sig. (2-tailed) & .000 \\
\hline
\end{tabular}

a. Wilcoxon Signed Ranks Test

b. Based on negative ranks.

\section{DISCUSSION}

Orbital fractures are usually seen in young adults, as evidenced by Kakibuchi et $\mathrm{al}^{3}{ }^{3}$ who reported a mean age of 23.5 years in their study of orbital blow out fractures, and Hatton et al, ${ }^{11}$ who reported 96 cases of orbital fractures in patients under the age of 18 years, most of whom were males. These results are consistent with our study, which consisted of only males with a mean age of $28 \pm 2.47$ years. In our study, the causes of the fractures were assaults, sports and motor vehicle accidents, which are similar to the already published literature. ${ }^{11,12}$ In the case series of Hatton et al, there was one case with associated globe rupture, indicating that globe injury should always be carefully excluded while managing orbital fractures.

Most of the fractures occur due to accident or assaults. The mode of trauma was a fist or ball in $70 \%$ of our cases. All the patients in our study were males due to the likelihood of males coming across accidents and being involved in the fights. The trauma typically occurred due to an object bigger than $5 \mathrm{~cm}$. Other studies also report similar aetiology. ${ }^{12,13}$ In two of our 
cases police investigation was needed. One should always address medico-legal aspects (e.g. photography, records written in details and securely stored) while dealing with these cases.

During the clinical examination any associated ocular, neuronal or head injury should be carefully excluded. We excluded any case with such associated disorders from this series. Although we managed to get Lees' screen (Hess) test in $60 \%$ of our cases, but it was not quite possible to obtainit in all cases, due to restricted resources and unavailability in some cases. All the patients of OBF should be advised to avoid blowing the nose as there have been reports of orbital emphysema and cellulites following this manoeuvre in the cases with orbital injury. ${ }^{14,15,16}$ We counselled all the patients to refrain from blowing the nose and started them on broad-spectrum antibiotics. The zero incidence of peri-orbital emphysema or infection in our case series can be attributed to this precaution. Thin slice $(2-3 \mathrm{~mm}) \mathrm{CT}$ scan images provide the most relevant information regarding orbital floor fracture, therefore we requested axial/coronal sections and bone density windows with special attention to orbital floor and medial wall depending upon clinical assessment in all our cases. In a couple of cases where direct coronal imaging was not possible reconstructed image gave enough guidelines to plan for surgery. Recent studies have also shown that CT imaging with coronal and axial images is superior to conventional radiography. ${ }^{17}$

The use of sterilized X-ray film as orbital implant is associated with low cost, easy availability, and improved support to the orbital floor without any aggravated inflammation. The sheet of X-ray film can be stabilized at the anterior orbital rim by merely suturing the periosteum, preventing anterior migration. It is well-supported by surrounding bone in smallmedium sized fractures. As the implant does not require fixation, the risk of iatrogenic trauma to the infraorbital nerve through screw placement is reduced. However, as the X-Ray film implant cannot be fixed to bone, the cases with larger fractures without an intact maxilla-ethmoidal strut are not suitable for this material. The first case report of the use of an autoclaved X-ray film for management of orbital floor fracture also promoted this improvisation for lowmiddle income countries as the film is tough, provides support and healing occurs within three weeks. It is also easily available for use at a very low cost. ${ }^{18}$ Although, Insul et $\mathrm{al}^{9}$ reported good outcome in 56 patients with the use of X-ray film, they encountered a case of pseudo-capsule formation around the film leading to recurrent proptosis. We did not come across any such complication in our series. Recent studies show that timing of surgery is not much important while repairing orbital floor fractures, even delayed surgery can give functional and cosmetic benefits. ${ }^{19}$ Moreover, it has also been shown that postoperative imaging in the absence of persistent clinical symptoms has no additional benefit in determining the complication rate. ${ }^{20}$ Consequently, we did not obtain postoperative images of the participants in our study.

Limitations of this case series is the retrospective study design, small sample and short follow-up.

\section{CONCLUSION}

Sterilized x-ray film is a safe, and low cost implant material for the repair of small to medium-sized orbital blowout fractures. It is well tolerated and readily available in all the hospitals at no added cost compared with other implant materials. Our case series provides evidence of its safety in treating orbital floor and medial wall fractures. It can provide an excellent alternative for orbital implants in countries with low healthcare spending, and can improve healing outcomes significantly for affected patients.

\section{Ethical Approval}

The study was approved by the Institutional review board/ Ethical review board. (1003/RC/KEMU).

\section{Conflict of Interest}

Authors declared no conflict of interest.

\section{Acknowledgment}

Thank are due to Miss Hafiza Ummara Rasheed for helping in statistical analysis.

\section{REFERENCES}

1. Salmon JF. Trauma In: Kanski's Clinical Ophthalmology. $9^{\text {th }}$ edition. Elsevier, 2020: p. 892-896.

2. McNab AA. A manual of orbital and lacrimal surgery. $2^{\text {nd }}$ edition. Butterworth Heinemann, 1998: p.77-82.

3. Kakibuchi M, Fukazawa K, Fukuda K, Matsuda K, Kawai K, Tomofuji S, et al. Combination of transconjunctival and endonasal-transantral approach in the repair of blowout fractures involving orbital floor. Br J Plast Surg. 2004; 57 (1): 37-44. 
4. Dubois L, Steenen SA, Gooris PJ, Bos RR, Becking AG. Controversies in orbital reconstruction-III. Biomaterials for orbital reconstruction: a review with clinical recommendations. Int J Oral Maxillofac Surg. 2016; 45: 41-50.

5. Gunarajah DR, Samman N. Biomaterials for repair of orbital floor blowout fractures: a systematic review. J Oral Maxillofac Surg. 2013; 71: 550-570.

6. Van Leeuwen AC, Ong SH, Vissink A, Grijpma DW, Bos RR. Reconstruction of orbital wall defects: recommendations based on a mathematical model. Exp Eye Res. 2012; 97: 10-18.

7. Wajih WA, Shaharuddin B, Razak NH. Hospital Universiti Sains Malaysia experience in orbital floor reconstruction: autogenous graft versus medpor. J Oral Maxillofac Surg. 2011; 69: 1740-1744.

8. Boyette JR, Pemberton JD, Bonilla-Velez J. Management of orbital fractures: challenges and solutions. Clin Ophthalmol. 2015; 9: 2127-2137.

Doi:10.2147/OPTH.S80463.

9. Insull EA, Hart RH, Sloan BH, Ben-Simon GJ, McNab AA. Use of X-ray Film Implant for the Repair of Orbital Fractures. Ophtha Im Plast Reconst Surg. 2013; 29 (5): 393-395.

10. Grob S, Yonkers M, Tao J. Orbital Fracture Repair. Semin Plast Surg. 2017; 31 (1): 31-39. Doi: 10.1055/s0037-1598191.

11. Hatton MP, Watkins LM, Rubin PA. Orbital fractures in children. Ophthal Plast Reconstr Surg. 2001; 17 (3): 174-179.

12. Karsteter PA, Yunker C. Recognition and management of an orbital blowout fracture. J Orthop Sports Phys Ther. 2006; 36 (8): 611-618.

13. Yazici B, Hammad AM, Meyer DR. Lacrimal sac Dacryoliths: Predictive factors and clinical characteristics. Ophthalmol 2001; 108 (7): 1308-1312.

14. Iliadelis E, Karabatakis V, Sofoniou M. Dacryoliths in chronic dacryocystitis and their composition (spectrophotometric analysis). Eu J Ophthalmol. 1999; 9 (4): 226-228.

15. Ye LX, Sun XM, Zhang YG, Zhang Y. Materials to facilitate orbital reconstruction and soft tissue filling in posttraumatic orbital deformaties. Plast Aesthet Res. 2016; 3: 86-91. Doi.10.20517/2347-9264.2015.122.
16. Kim HS, Jeong EC. Orbital Floor Fracture. Arch Craniofac Surg. 2016; 17 (3): 111-118.

Doi:10.7181/acfs.2016.17.3.111.

17. Shah S, Uppal SK, Mittal RK, Garg R, Saggar K, Dhawan R. Diagnostic tools in maxillofacial fractures: Is there really a need of three-dimensional computed tomography? Indian J Plast Surg. 2016; 49 (2): 225. Doi: 10.4103/0970-0358.191320.

18. Shoaib CK, Ali K, Mukhtar MA. Management of orbital floor fracture with autoclaved x-ray film. Pak Armed Forces Med J. 2008; 58 (3): 353-356.

19. Scawn RL, Lim LH, Whipple KM, Dolmetsch A, Priel A, Korn B, et al. Outcomes of Orbital Blow-Out Fracture Repair Performed Beyond 6 Weeks After Injury. Ophth Plast Reconstr Surg. 2006; 32 (4): 296301. Doi: 10.1097/IOP.0000000000000511.

20. Carpenter D, Shammas R, Honeybrook A, Brown CS, Chapurin N, Woodard CR. The role of postoperative imaging after orbital floor fracture repair. Craniomaxillofac Trauma Reconstr. 2018; 11 (2): 96101. Doi: 10.1055/s-0038-1625949

\section{Authors' Designatin and Contribution}

Zahid Kamal Siddique; Professor: Concepts, Design, Literature search, Data acquisition, Manuscript review.

Qudsia Anwar Dar; Senior Registrar: Literature search, Data analysis, Statistical analysis, Manuscript preparation, Manuscript editing.

Amna Farooq; Post Graduate Trainee: Literature search, Data acquisition, Data analysis, Manuscript review.

Muhammad Ijaz Anjum; Post Graduate Trainee: Design, Literature search, Data acquisition, Manuscript review.

Muhammad Mohsin Ali; House Surgeon: Literature search, Manuscript editing. 